\title{
Correction to: Emergent D-Instanton as a Source of Dark Energy
}

\section{Deobrat Singh ${ }^{1,2}$}

Published online: 23 July 2019

(C) Sociedade Brasileira de Física 2019

Correction to: Brazilian Journal of Physics (2019) 49:249-255

https://doi.org/10.1007/s13538-019-00635-y

In the original article Supriya Kar was listed as a co-author without his permission. The sole author of this article is Deobrat Singh

The online version of the original article can be found at https://oi.org/ 10.1007/s13538-019-00635-y

Deobrat Singh

deobratsingh10@gmail.com; deobratsingh10@ mitsgwalior.in

1 Department of Physics \& Astrophysics, University of Delhi, New Delhi 110 007, India

2 Department of Applied Science, Madhav Institute of Technology and Science, Gwalior, India 